\title{
Introduction
}

\section{Chinese transnational students and the global education hierarchy}

\section{Anders Sybrandt Hansen and Stig Thøgersen}

Recent years have seen a tremendous increase in transnational education mobility. The two trends of international integration and marketisation of higher education have made for a situation in which increasing numbers of aspiring young people worldwide seize the opportunity to study abroad as part of their higher education. No other nation sends more students abroad than China. In 2014, 459,800 students left the country to study abroad (Ministry of Education 2015); and 22 per cent of all international students enrolled in tertiary education in OECD countries in 2012 came from China (OECD 2014: 350). To explore the many dimensions of this huge wave of educational migration we hosted a conference at Aarhus University with the title Chinese Students Abroad: Reflections, Strategies and Impacts of a Global Generation in March 2014. ${ }^{1}$ The initial versions of the first three articles in this issue by Heidi Ross and Yajing Chen, Kirsten Jæger and Malene Gram, and Qing Gu were presented at this conference. ${ }^{2}$ The fourth article, by Naomi Yamada, examines the education of ethnic minorities inside China and thereby throws light on another, but related, effect of the marketisation of Chinese education.

In this introduction we outline three themes that provide a context for Chinese students' study-abroad experience. First, their preferences and decisions about where to study are to a large extent shaped by their perceptions of a global education hierarchy, a 'moral geography' that defines where the most valuable knowledge and qualifications can be found. Second, the Chinese state has designed strategies and policies through which it tries to place students' individual study-abroad projects inside a framework of national development. Finally, studying abroad is a deeply personal experience with a strong impact on the biography and world view of the single Chinese student. 


\section{Global education hierarchies, moral geographies and the rise of China}

A bewildering number of universities worldwide accept foreign students, yet the number of applicants received by different destination countries and institutions shows that student flows are guided by perceptions of a global education hierarchy. At the highest macro level this hierarchy is reflected in the fact that the OECD countries in 2012 received 3.4 million foreign students, amounting to three foreign students for every OECD citizen studying outside his or her country of origin (OECD 2014: 350).

As foreign students provide revenues for host universities and host societies in general, this student flow is accompanied by an overall money flow from developing to developed countries. And the national economic gain from having universities that rank high in global education hierarchies is considerable. For example, the U.K. case shows that non-EU students paid GBP3.2 billion in tuition fees during the academic year 2011-12, while the off-campus expenditure of non-U.K. students was estimated at GBP4.9 billion (Universities UK 2014). A related issue is that of 'brain drain'. With the opening of a global market in higher education, argues Simon Marginson, the value assigned to places of higher education in developing countries is deflated in comparison with an academic career in developed countries (Marginson 2006). A number of institutional and cultural factors support this global education hierarchy. Firstly, tuition fees and academic admission requirements make for differential access to institutions that consequently appear more or less exclusive (see Ross and Chen in this issue). Secondly, an industry of world university rankings has mushroomed on the promise of calculating the relative academic quality of the world's universities. The resulting ranking tables have become extremely influential in directing students' aspirations and are perhaps as close as we can get to an aggregated perception of the global education hierarchy. China is a very active player in this game through the Academic Ranking of World Universities conducted by Shanghai Jiaotong University. Thirdly, there is the role of language. English is firmly established as the principal language of academic publication, it is the dominant language of international business and politics, and it is by far the most dominant second language taught on a global scale. Universities in native English-speaking countries attract a disproportionately large number of foreign students partly because they provide access to the dominant academic language and to native English-speaking social environments 
(Marginson 2006). Finally, there is the highly important yet relatively unexplored role of cultural imaginaries of places, or what Xin Liu calls 'moral geography' (Liu 2000: 6; cf. Bal and Willems 2014; Gardner 2008). By this we mean to point to the fact that nations on the global map, and regions and places within nations, are symbolically ordered in various ways as possessing different qualities that offer different options for financial gain, intellectual growth and personal development. We argue that the imaginary of a moral geography is particularly robust in contemporary China.

This moral geography carries a developmental ideology. When we contrast developed and developing nations in the contemporary world, logic dictates that the two are contemporaneous, and yet our language asserts that one side is ahead of the other. This is a basic moral judgement that is mapped onto geography - some places are ahead, some behind; some are adequate, some are lacking. This developmental terminology is especially pervasive in the People's Republic of China (PRC) where public perceptions routinely order places - from continents to villages - according to whether they are developed ( $f a d a$ ) or backward (luohou, which literally means 'fallen behind'). There are at least two socio-historical reasons for this. The most obvious is that the ideology of the Communist Party of China (CPC) is rooted in historical materialism and has inherited from this tradition a linear, stageby-stage view of historical development (see Yamada's article in this issue). Even today the image of development as a ladder with clearly defined steps lives on in Chinese public and state discourses regardless of whether or not Chinese society can meaningfully be said to be moving in the direction of communism.

Extreme socioeconomic disparities mark contemporary China, and this is a second reason for the strong hold of the moral geography with its imaginary of hierarchies of place. It is common sense in the PRC that the urban is superior to the rural, that east China is superior to west China, and perhaps even, that downhill is superior to uphill as the poorest villages can usually be found in the mountains (Johnston 2013; Murphy 2004). This is also the logic behind the preferential educational policies for national minorities, discussed by Yamada in this issue, because places inhabited by non-Han ethnic groups are perceived to exist near the bottom of these hierarchies. At the other end of the spectrum, China's cities are divided into tiers by commercial actors and state agencies alike. A new word - Beishangguang - denotes the three agreed-upon first-tier cities (Beijing, Shanghai and Guangzhou), and thereby neatly sums up 'where one ought to live and work'. 
This moral geography extends beyond China's national borders. In her extensive study of Chinese students' aspirations during the preceding decade, Vanessa Fong points out the currency of the term 'abroad' (guowai). In the moral imagination of her student informants, 'abroad' was virtually always compared favourably to China, and particularly so in the field of education (Fong 2011). In this context the term 'abroad' did not designate just any place outside China's national borders, but rather 'developed countries', or, more precisely: the U.S., the U.K., Canada, Western European nations, Australia, New Zealand, Japan, South Korea and Singapore. It is worth noting in this context that while the larger-than-life expectations of Fong's interlocutors about life 'abroad' were frequently let down, the position of these countries at the apex of the place hierarchy remained secure.

Other sources validate Fong's findings. For example, the 2014 Hurun Report found that 60 per cent of China's millionaires were considering migration or had already moved abroad. A follow-up survey found that access to education abroad for their children ranked alongside pollution and food safety issues as the top three stated reasons for considering migration among China's rich (Hurun Report 2014). For people without migration plans, an exchange stay or a degree from abroad is considered a valuable asset on the Chinese labour market. With the increasing number of returnees, students at prestigious Chinese universities maintain that it is becoming the norm for employers that applicants should have some kind of overseas experience (Hansen 2015; see also Gu's article in this issue). Even children of China's political leaders prefer studying abroad, such as president Xi Jinping's daughter Xi Mingze, who graduated from Harvard in 2014.

The remarkable increase in the number of Chinese transnational students, however, coincides with the rise of China as a global superpower and this has created new dilemmas for the imaginary of a moral geography. On the one hand, a foreign degree is no longer in itself a guarantee of attractive employment. As China has become integrated into the global education hierarchy, different levels of prestige are accorded to different kinds of overseas credentials and derogatory terms such as 'foreign trash' (waiguo laji) are sometimes used in the social media about graduates from foreign institutions that do not appear in the international ranking tables. On the other hand, Chinese top universities often prefer hiring academic staff with foreign degrees and many universities now treat foreign experience as a requirement for promotion. In this sense, the Chinese educational culture does not necessarily challenge the global education hierarchy as such, at least not 
in the short run. Chinese universities accept that they take part in a global competition and the Chinese state invests heavily in top universities such as Peking University and Tsinghua University in order to see them move closer to the top of the ranking tables.

The articles by Ross and Chen and by Jæger and Gram show how Chinese students' ideas of a global education hierarchy are reflected in their choice of universities and majors as well as in their perceptions of academic quality. Ross and Chen's case study also demonstrates how Chinese students' hierarchical and instrumental thinking about education is implicitly supported by the receiving institution and its admission criteria. Seen in this light, the focus on exam scores and ranking that has characterised the Chinese education system since the reintroduction of the national university entrance exams (gaokao) in the late 1970s suddenly appears less 'exotic' and more as part of a global trend.

\section{Chinese state policies on overseas studies}

In recent decades the Chinese government has developed a range of policies that aim at regulating the interaction between China and the global education hierarchy outlined above. The Chinese state has traditionally taken a strong interest in the educational migration of its citizens and the strategic advantages this could bring to the nation. As early as the 1870s, the imperial government sent large groups of young boys to the United States to acquire 'Western learning', the lack of which was perceived to be a key factor behind China's defeat in the Opium Wars (1839-1842 and 1856-1860). These students were called back to China in 1881 because the imperial government feared that they were becoming too Americanised, but many of them later played important roles in China's modernisation (Rhoads 2011). Later waves of Chinese students going overseas to the West and Japan during the Republican period (1912-1949) and to the Soviet Union and Eastern Europe during the 1950s confirmed the reputation of studying abroad as an important strategy for strengthening the nation and, from the perspective of the individual student, as a road to professional success and social prestige.

There was a decade-long break in overseas studies during the Cultural Revolution (1966-1976), but the reformist leadership that came to power in 1978 led by Deng Xiaoping saw education as one of the main keys to economic development and soon decided to end China's academic isolation. During the Cultural Revolution in the 1960s and 1970s, Chinese urban youth 
were collectively sent 'down to the countryside' in order to learn from the peasants' practice-based approach to knowledge and to become 'revolutionary successors'. Deng turned this epistemology upside-down and started sending small groups of young elite students to Western countries to learn from the 'advanced' and 'developed' nations. Most of these students were academically extremely successful in their host countries, but much to the disappointment of Chinese leaders, the large majority decided not to return to China after graduation. After the army crushed the widespread student demonstrations in Beijing and other major Chinese cities in June 1989 this trend became even more pronounced and left China with a 'brain drain' problem that could not be ignored.

The Chinese government tried to solve this in 1992 when it presented a new policy with the slogan: 'Support studies abroad, encourage [graduates] to come back to China, and grant them freedom to come and go' (zhichi liuxue, guli huiguo, lai-qu ziyou). Rather than forcing students to come back it was now made attractive for them to include China in their career plans. A further step in this direction came in 2001, when the state basically dropped its fear of brain drain and encouraged graduates to 'serve the nation' without necessarily 'returning to the nation'. Even if they worked as researchers and technicians in foreign universities and enterprises, graduates of Chinese origin were still believed to be able to facilitate China's transition to a knowledge economy by linking China up with global science and technology networks (Zweig, Fung and Han 2008).

It will be evident even from this brief overview that educational migration is considered to be a field of great strategic importance for China and most students who go abroad are well aware of the relevant state policies. However, while the Chinese state directly selected and supported students who went abroad in the 1950s and 1960s, and even in the first years after educational exchanges were resumed in the late 1970s, its present power to control education migration in detail is limited. In 2014 only 8 per cent of the Chinese students who went abroad were financed through public sources (Ministry of Education 2015), showing that the vast majority invested their own resources and, to an even larger extent, their families' funds in their overseas studies. Like many other fields of Chinese economic and social life, studying abroad has been privatised. Official guidelines and policies constitute the macro framework for Chinese educational migration, but the decision-making power as well as the financial burden has shifted decisively to individual students and their families. This is reflected in the articles 
selected for this issue, which all emphasise the perspective of the individual student in the analysis.

\section{Studying abroad as personal development}

For the young Chinese involved, studying abroad has first and foremost become a personal project (see in particular the article by $\mathrm{Gu}$ in this issue). This reflects deeper changes in Chinese society. As Yunxiang Yan (2009) has shown, liberation from many of the political and social restrictions of the Mao era, combined with the dissolution of socialist collectives, has led young Chinese into an enforced individualisation with all the risks and uncertainties involved. State welfare has been dramatically reduced and the Maoist critique of individualism has become a thing of the past. In its place we find a widespread assumption that the individual is wholly responsible for his or her academic and economic success, and that the route to such success goes through self-development, to which higher education is the key.

It has therefore become a crucial aspect of the generational destiny of Chinese citizens born after 1980 that they are facing seemingly limitless options for upward mobility, but also an increasingly intense competition from gradually more well-educated peers (Fong 2011; Kipnis 2011). The entire generation is brought up to be 'striving individuals' who live under a constant pressure to develop into ever more competitive subjects (Yan 2013). Under the influence of the widespread perception of the global education hierarchy, studies abroad, mainly in the West, have become a means of selfdevelopment, a way of integrating transnational values and competencies into individual biographies. This is a highly challenging process that leads to a broad range of different outcomes at the individual level, and the encounter between Chinese students and Western universities can be problematic. In a review of the academic literature on Chinese students abroad, Henze and Zhu (2012) found a general focus on problems such as language difficulties, plagiarism, limited participation in classroom activities and isolation in co-national groups (see also Ross and Chen in this issue). In the same vein, a recent report, which received much media attention in both China and abroad, found that 8,000 Chinese students were expelled from U.S. universities in 2014 alone, mainly because of poor academic performance or cheating (Wall Street Journal 2015).

However, if we simply treat Chinese transnational students as a 'problematic' student body we miss the opportunity to understand what their 
encounter with Western institutions can tell us both about this generation of young Chinese and about the way individuals and institutions shape and are shaped by the internationalisation of higher education. The large majority of the students who go abroad have strong aspirations to develop personally and professionally (Hansen and Thøgersen 2015; Thøgersen 2012, 2015). The following articles contribute different perspectives on their struggles to achieve these aims.

\section{Featured articles}

This themed issue features four original research articles addressing different aspects of contemporary educational culture in the People's Republic of China (PRC) and its interactions with the global education hierarchy. Three articles speak to the topic of coping with culture in transnational education, while the final article addresses the related issue of minority education in the PRC and the U.S. respectively.

In their article, Heidi Ross and Yajing Chen confront familiar conundrums in the integration of Chinese transnational students with U.S. universities. While this group makes up a great source of revenue for U.S. universities, a number of challenges are commonly associated with their classroom performance and campus integration. The article addresses three of these issues: Why are Chinese students silent in class? Why do they stick together? Why are they so instrumental? Insisting that a broad notion of Chinese culture does not capture the dynamics at play, Ross and Chen redirect our attention to the interaction between the host institution and the Chinese student cohort, and the ways in which U.S. sociocultural and educational norms both constrain and enable different kinds of engagement. For example, they use the case of a prestigious Midwest business school to show how the school's focus on ranking and exam scores reinforces what is often described as a 'typically Chinese' instrumental approach to education, even though this is at odds with the professed ideals of U.S. liberal arts education.

Kirsten Jæger and Malene Gram in their article explore the perceptions of academic quality among two groups of students abroad: Chinese students at a Danish university and Danish students at Chinese universities. Linking the micro-ethnographic level to the global education hierarchy, they find that their case study confirms the relative positioning of Western, in this case Danish, and Chinese institutions in the global scheme of things. This is evident in the different attitudes of the two groups to the local education 
practices they come across in the foreign context. The Chinese cohort, Jæger and Gram shows, was initially challenged by the problem-based learning methods employed at the Danish university, but gradually adopted the academic standards of the host institution as valid criteria. The Danish cohort, on the other hand, is shown to have generally been both more critical of the academic standards of their Chinese host institutions and remarkably confident in their ability to judge the relative academic quality of teaching at the different universities - even though they may have missed opportunities to learn in new ways in the process.

Qing $\mathrm{Gu}$, in her article, provides an inside view from Chinese transnational students in the U.K. and from returnees to China. Based on longitudinal data from three studies, Qing $\mathrm{Gu}$ argues that if we are fully to grasp the significance of studies abroad, we need to pay attention to emotions as the link between social structures and individual agency. The importance of studying abroad, the author finds, can first and foremost be found in its effects on identity. The article shows how studies abroad coupled with transnational ties stimulate increasingly self-reflexive and culturally reflexive identities. Consequently, Chinese transnational students must juggle insider and outsider roles in the context of both their host country and their country of birth. But this familiarity with different cultural perceptions is simultaneously a source of personal growth and a source of pride to many returnee students, who perceive themselves as having become especially skilled at dealing with intercultural relations.

Based on her fieldwork in Qinghai province in West China, Naomi Yamada's article discusses preferential educational policies for China's ethnic minorities, which she compares to affirmative action in the U.S. The article paints a fascinating picture of how global education hierarchies are mirrored at the national level. Just as Chinese students abroad must master English, the global academic language, ethnic minority students on the Tibetan plateau must master Mandarin Chinese, the national academic language, if they want to pursue higher education. And much like the Chinese students in Jæger and Gram's article who learned to accept 'Western' academic standards, ethnic minority students in Yamada's study had to accept the ostensibly objective criteria of the Chinese university entrance exam, the gaokao, in which the preferential policies afforded minority populations gives them only a small advantage. Another striking similarity between Chinese students abroad and ethnic minority students aspiring for university education in China is the change 'from free to fee' mentioned by 
Yamada. Ethnic minority students whose gaokao scores qualify them for previously free college preparatory courses now pay large tuition fees. They have become 'self-paying' (zifei), like the large majority of Chinese students abroad, while the Chinese state has re-directed its investments towards a few elite universities that it aspires to make internationally competitive.

Together, the four articles offer fascinating insights into how the internationalisation of higher education is both reinforcing moral geographies and changing academic institutions around the world, and particularly how Chinese students relate to and interact with the global education hierarchy as a group and as individuals.

\begin{abstract}
Anders Sybrandt Hansen has a PhD in anthropology and is an Associate Professor at the School of Culture and Society, Aarhus University. He has published on university students' engagement with the CPC, on migrants' integration with the global economy, and on contemporary PRC historiography. His current work takes a phenomenological approach to the study-abroad experiences of Chinese students.

Email: etnoash@cas.au.dk
\end{abstract}

Stig Thøgersen is professor of China Studies, School of Culture and Society, Aarhus University. He has published extensively on the history of Chinese education and on social, cultural and political change in twentieth and twenty-first century rural China. His present research projects focus on Chinese educational migration and on changing perceptions of childhood in China.

Email: stig.thogersen@cas.au.dk

\title{
Notes
}

1. The conference was generously supported by the Aarhus University Research Foundation and the Carlsberg Foundation. We want to thank all participants in the conference for their constructive inputs and feedback.

2. Revised versions of other papers from the conference addressing the anthropology of Chinese transnational education migration appears in the Journal of Current Chinese Affairs 44, no. 3, October 2015. 


\section{References}

Bal, Ellen and Willems, Roos (2014) 'Introduction: aspiring migrants, local crises and the imagination of futures "away from home"', Identities: Global Studies in Culture and Power 21, no. 3: 249-258.

Fong, Vanessa (2011) Paradise Redefined: Transnational Chinese Students and the Quest for Flexible Citizenship in the Developed World, Stanford: Stanford University Press.

Gardner, Katy (2008) 'Keeping connected: security, place, and social capital in a "Londoni” village in Sylhet', Journal of the Royal Anthropological Institute 14: 477-495.

Hansen, Anders S. (2015) 'The temporal experience of Chinese students abroad and the present human condition', Journal of Current Chinese Affairs 44, no. 3: 9-77.

Hansen, Anders S. and Thøgersen, Stig (2015) 'The anthropology of Chinese transnational educational migration', Journal of Current Chinese Affairs 44, no. 3: 3-14.

Henze, Jürgen and Zhu, Jiani (2012) 'Current research on Chinese students studying abroad', Research in Comparative and International Education 7, no. 1: 90-104.

Hurun Report (2014) Immigration and the Chinese HNWI 2014, Shanghai: Hurun Research Institute, < http://www.hurun.net/en/ArticleShow.aspx?nid = 1502> (accessed 26 June 2015).

Johnston, James (2013) 'Filial paths and the ordinary ethics of movement', in Charles Stafford (ed.) Ordinary Ethics in China, London: Bloomsbury, 45-65.

Kipnis, Andrew (2011) Governing Educational Desire: Culture, Politics and Schooling in China, Chicago, IL: University of Chicago Press.

Liu, Xin (2000) In One's Own Shadow: An Ethnographic Account of the Condition of PostReform Rural China, Berkeley: University of California Press.

Marginson, Simon (2006) 'Dynamics of national and global competition in higher education', Higher Education 52, no. 1: 1-39.

Ministry of Education of the People's Republic of China (2015) '2014 nianduwoguochuguoliuxuerenyuanqingkuang' [The Situation in 2014 of Chinese going abroad to study], < http://www.moe.edu.cn/publicfiles/business/htmlfiles/moe/s5987/201503/ 184499.html > (accessed 5 July 2015).

Murphy, Rachel (2004) 'Turning peasants into modern Chinese citizens: "population quality” discourse, demographic transition and primary education', China Quarterly 177: 1-19.

OECD (2014) 'How many students study abroad and where do they go?', in Education at a Glance 2014: OECD Indicators, OECD Publishing, < http://www.oecd.org/edu/ Education-at-a-Glance-2014.pdf > (accessed 24 June 2015).

Rhoads, Edward J.M. (2011) Stepping Forth into the World: The Chinese Educational Mission to the United States, 1872-1881, Hong Kong: Hong Kong University Press. 
Thøgersen, Stig (2012) 'Chinese students' great expectations: prospective pre-school teachers on the move', Learning and Teaching: The International Journal of Higher Education in the Social Sciences 5, no. 3: 75-93.

Thøgersen, Stig (2015) “"I will change things in my own small way”: Chinese overseas students, “Western” values, and institutional reform', Journal of Current Chinese Affairs 44, no. 3: 103-124.

Universities UK (2014) The Impact of Universities on the UK economy, London < http://www.universitiesuk.ac.uk/highereducation/Documents/2014/ TheImpactOfUniversitiesOnTheUkEconomy.pdf > (accessed 24 June 2015).

Wall Street Journal (2015) 'U.S. schools expelled 8,000 Chinese students', 6 June < http://blogs.wsj.com/chinarealtime/2015/05/29/u-s-schools-expelled-8000chinese-students-for-poor-grades-cheating/ > (accessed 5 July 2015).

Yan, Yunxiang (2009) The Individualization of Chinese Society, Oxford: Berg.

Yan, Yunxiang (2013) 'The drive for success and the ethics of the striving individual', in Charles Stafford (ed.) Ordinary Ethics in China Today, London: Bloomsbury, 263-291.

Zweig, David, Fung, Chung Siu and Han, Donglin (2008) 'Redefining the brain drain. China's “diaspora option”, Science, Technology \& Society 13: 1-33. 